\title{
Pengaruh Komunikasi Nonverbal dalam mewujudkan Komunikasi yang Efektif antara Agen dan konsumen PT. Axa Financial Indonesia cabang Medan
}

\author{
Ara Auza* \\ Program Studi Ilmu Komunikasi, Fakultas Ilmu Sosial dan Ilmu Politik \\ Universitas Medan Area, Indonesia
}

Diterima: Februari 2019; Disetujui: Maret 2019; Dipublish: April 2019

*E-mail: ara@staff.uma.ac.id

\begin{abstract}
Abstrak
Penelitian ini berjudul Pengaruh Komunikasi Nonverbal dalam mewujudkan Komunikasi yang Efektif antara Agen dan konsumen PT. Axa Financial Indonesia cabang Medan. Penelitian ini bertujuan untuk mengetahui proses Komunikasi Nonverbal yang dilakukan oleh Agen Asuransi PT. Axa Financial Indonesia cabang Medan; untuk mengetahui peranan Komunikasi nonverbal dalam mewujudkan Komunikasi yang Efektif antara Agen dan Konsumen PT. Axa Financial Indonesia cabang Medan; dan untuk mengetahui bentuk-bentuk komunikasi nonverbal yang dilakukan agen asuransi PT. Axa Financial Indonesia dapat mewujudkan komunikasi efektif kepada konsumen. Teori yang digunakan dalam penelitian ini adalah teori komunikasi antar pribadi, komunikasi non verbal dan komunikasi efektif. Metodologi penelitian ini dimaksudkan untuk menggambarkan bagaimana peneliti dalam menggambarkan tentang tata cara pengumpulan data yang diperlukan, serta analisis data. Metode dalam penelitian ini adalah metode studi kasus. Informan dalam penelitian ini berjumlah 5 informan terdiri dari 2 (dua) agen asuransi dan 3 (konsumen) asuransi PT. AXA Financial Indonesia Cabang Medan. Hasil penelitian Komunikasi nonverbal yang sering digunakan oleh agen adalah penampilan fisik. Penampilan fisik yang rapi dan menarik banyak diperhatikan agen. Faktor yang dominan ketika melakukan presentasi adalah intonasi/nada suara yang jelas dan gerakan anggota tubuh/kinesik seperti tangan dan tatapan mata.
\end{abstract}

Kata Kunci: Komunikasi Nonverbal, Komunikasi Antar Pribadi Komunikasi Efektif

\begin{abstract}
This study entitled The Effect of Nonverbal Communication in realizing Effective Communication between Agents and consumers of PT. Axa Financial Indonesia, Medan branch. This study aims to determine the process of Nonverbal Communication carried out by Insurance Agents of PT. Axa Financial Indonesia Medan branch; to find out the role of nonverbal communication in realizing Effective Communication between Agents and Consumers PT. Axa Financial Indonesia Medan branch; and to find out forms of nonverbal communication by insurance agents PT. Axa Financial Indonesia can realize effective communication with consumers. The theory used in this study is the theory of interpersonal communication, non-verbal communication and effective communication. The research methodology is intended to describe how researchers describe the procedures for collecting data needed, as well as analyzing data. The method in this study is a case study method. The informants in this study were 5 informants consisting of 2 (two) insurance agents and 3 (consumers) insurance PT. AXA Financial Indonesia Medan Branch. Research results Nonverbal communication that is often used by agents is physical appearance. The neat and attractive physical appearance was noticed by agents. The dominant factor when making a presentation is the clear tone of voice and movement of the limbs / kinesik such as the hands and eyes.
\end{abstract}

Keywords: Non Verbal Communication, Interpersonal Communication, Effective Communication

How to Cite: Auza, A. (2019). Pengaruh Komunikasi Nonverbal dalam mewujudkan Komunikasi yang Efektif antara Agen dan konsumen PT. Axa Financial Indonesia cabang Medan. Journal of Education, Humaniora and Social Sciences (JEHSS). 1 (3): 156-161. 
Ara Auza. Pengaruh Komunikasi Nonverbal dalam mewujudkan Komunikasi yang Efektif antara Agen dan

\section{PENDAHULUAN}

Proses komunikasi pada hakikatnya adalah proses penyampaian pikiran atau perasaan oleh seseorang (komunikator) kepada orang lain (komunikan). Adakalanya seseorang menyampaikan buah pikirannya kepada orang lain tanpa menampakkan perasaan tertentu. Pada saat lain seseorang menyampaikan perasaannya kepada orang lain tanpa pemikiran. Tidak jarang pula seseorang menyampaikan pikirannya disertai perasaan tertentu, disadari atau tidak disadari (Effendy, 1999).

Komunikasi akan berhasil apabila pikiran disampaikan dengan menggunakan perasaan yang disadari; sebaliknya komunikasi akan gagal jika sewaktu menyampaikan pikiran, perasaan tidak terkontrol. Kita (manusia) akan melakukan komunikasi nonverbal seperti menggunakan bahasa tubuh agar orang lain dapat memahami perasaan kita. Seseorang yang sedang jatuh cinta boleh menulis surat kepada pacarnya dan mengungkapkan gelora kerinduannya. Dia akan tertegun, kerena tidak menemukan kata-kata yang tepat untuk menyatakan sesuatu yang begitu mudah diungkapkan melalui pesan nonverbal. Menurut Mahrabian (1967), hanya 7\% perasaan kasih sayang dapat dikomunikasikan dengan kata-kata. Selebihnya 38\% dikomunikasikan lewat suara, dan 55\% dikomunikasikan melalui ungkapan wajah (senyum, kontak mata, dan sebagainya) (dalam Rakhmat, 2005).

Komunikasi nonverbal digunakan untuk memastikan bahwa makna yang sebenarnya dari pesan-pesan verbal dapat dimengerti atau dapat dipahami. Keduanya, komunikasi verbal dan nonverbal, kurang dapat beroperasi secara terpisah, satu sama lain saling membutuhkan guna mencapai komunikasi efektif (Sendjaja, 2004).

Komunikasi dikatakan baik apabila komunikasi itu efektif. Salah satu indikator keefektifan komunikasi adalah apabila memenuhi sejumlah syarat tertentu, dimana salah satunya adalah komunikasi yang mampu menimbulkan kesenangan diantara pihak yang terlibat. Komunikasi akan terus berlangsung selama kedua pihak merasa senang dan dihargai. Orang ingin kehadirannya tidak hanya dianggap bilangan, tetapi juga diperhitungkan.

Di sisi lain, fenomena asuransi di negeri ini semakin menarik untuk dicermati, dengan masuknya perusahan-perusahan multinasional semakin menambah ketatnya persaingan memperebutkan pasar. Sebagai salah satu Negara dengan populasi penduduk terbesar didunia, jumlah penduduk Indonesia saat ini, yaitu 229.964 .723 jiwa di situs Bank Dunia (http://www.google.com/publicdata). Indonesia menjadi pasar yang potensial bagi perkembangan bisnis asuransi. Saat ini, jumlah pemegang polis asuransi di Indonesia kurang lebih dua belas juta jiwa. Bandingkan dengan populasi penduduk Indonesia yang mencapai 220 juta jiwa. Ini artinya di Indonesia hanya sekitar enam persen. Sedangkan jumlah tertanggung (menjadi nasabah) mencapai 24 juta jiwa, atau sekitar 10-12 persen dari total penduduk Indonesia. Terdiri tertanggung (polis) individu sebanyak delapan juta jiwa dan 24 juta jiwa polis kumpulan. (http://asuransijiwaaxa.wordpress.com/)

Agen asuransi adalah front-line atau ujung tombak bagi perusahaan asuransi. Biasanya sebagian besar agen tersebut merupakan mitra bagi perusahaan asuransi, artinya mereka bukan merupakan pegawai tetap yang setiap bulan harus digaji oleh perusahaan, Pendapatan mereka berdasarkan angka penjualan yang mereka peroleh. Untuk perekutan agen biasanya tidak dipatok berdasarkan pendidikan, tetapi biasanya lebih kepada mereka yang memiliki pergaulan yang luas.

Agen asuransi yang merupakan ujung tombak bagi perusahaan asuransi dibekali kemampuan untuk berkomunikasi. Komunikasi yang efektif akan memudahkan bagi agen untuk menjual produk asuransi kepada calon pemegang polis asuransi. Masalahnya komunikasi merupakan proses kompleks, pesan yang disampaikan agen (komunikator) harus mudah dipahami calon pemegang polis.

Komunikasi antar pribadi antara agen dengan calon nasabah adalah salah satu cara yang paling efektif dalam memberikan informasi tentang produk asuransi kepada calon nasabah. Melalui komunikasi antar pribadi, seorang agen dapat memperkenalkan dan menjelaskan tentang produk jasa asuransi serta mengedukasi dan mengarahkan calon nasabah dalam memilih 触 http://mahesainstitute.web.id/ojs2/index.php/jehss 
asuransi yang sesuai dengan kemampuan dan kebutuhan mereka. Dengan komunikasi yang dilakukan secara langsung, kita lebih intim dengan orang lain dan hubungan antar pribadi kita diperkuat.

PT. Axa Financial Indonesia cabang Medan bagian dari Axa Financial Indonesia merupakan perusahaan asuransi jiwa yang seluruh sahamnya dimiliki oleh Axa Group. Axa Financial Indonesia merupakan perusahaan asuransi terbesar di dunia, peringkat pertama kategori World Largest Corporation dari Fortune Global 500 Edisi Juli 2008. Axa Financial Indonesia berdiri sejak tahun 1993, dan bergerak di jalur distribusi keagenan yang terus bertumbuh menjadi perusahaan asuransi jiwa yang dipercaya oleh lebih dari 36.000 nasabah di seluruh Indonesia. AXA Financial Indonesia berhasil menghantarkan agen terpilih sebagai nominasi Agent of The Year 2007 TOP Policy 2007, Top Income 2007 dan Top Premium 2007. Top Agent Award (TAA) 2008 yang merupakan ajang bergengsi dari Asosiasi Asuransi Jiwa Indonesia ini, yang bertujuan memberikan penghargaan terhadap agen-agen terbaik di dunia asuransi jiwa Indonesia. Suatu prestasi yang sangat baik bahwa AXA Financial Indonesia berhasil mendapatkan nominasi hampir di seluruh kategori acara. Ini merupakan bukti nyata bahwa agen-agen yang melayani nasabah merupakan agen professional yang diakui di kalangan perasuransian. (http://www.axafinancial.co.id)

Menarik ketika kita melihat bagaimana proses komunikasi yang dilakukan oleh agen PT. Axa Financial Indonesia sehingga mendapat banyak penghargaan dan memiliki banyak nasabah. Proses komunikasi adalah proses komplek yang satu sama lain dari unsur komunikasi terhubung untuk menghasilkan komunikasi efektif. Tetapi peneliti hanya fokus untuk meneliti komunikasi nonverbal yang dilakukan oleh agen PT. Axa Financial Indonesia.

\section{METODE PENELITIAN}

Metodologi penelitian ini dimaksudkan untuk menggambarkan bagaimana peneliti dalam menggambarkan tentang tata cara pengumpulan data yang diperlukan, serta analisis data. Metode dalam penelitian ini adalah metode studi kasus. Studi kasus adalah metode riset yang menggunakan berbagai sumber data (sebanyak mungkin data) yang bisa digunakan untuk meneliti, menguraikan dan menjelaskan secara komprehensif berbagai aspek individu, kelompok, suatu program, organisasi atau peristiwa secara sistematis (Kriyantono, 2007). Seorang peneliti harus mengumpulkan data setepat-tepatnya dan selengkap-lengkapnya dari kasus tersebut untuk mengetahui sebab-sebab yang sesungguhnya bilamana terdapat aspekaspek yang perlu diperbaiki (Nawawi, 1994).

Penelitian dilakukan dengan melakukan pengamatan langsung terhadap objek penelitian di lokasi penelitian. Semua hasil pengamatan dan wawancara mendalam akan dituangkan dalam pembahasan. Hasil pengamatan dan wawancara tersebut nantinya akan dianalisis, diinterpretasikan sesuai dengan tujuan penelitian.

\section{HASIL DAN PEMBAHASAN \\ Komunikasi Non Verbal}

Pengetahuan agen akan komunikasi nonverbal hanya terbatas pada penampilan fisik dan gerakan tubuh. Sedangkan indikator yang lain belum diperhatikan secara serius. Ketika akan mempresentasikan asuransi pada calon nasabah agen hanya bergantung pada pengalamannya sebagai agen.

Intonasi menjadi penting bagi agen ketika berbicara dengan nasabah. Agen memperhatikan indikator ini dengan berbicara jelas. Agen hanya melakukan penekanan pada hal-hal penting yang harus diketahui oleh nasabah. Intonasi yang digunakan adalah jelas dalam artian tidak terlalu keras dan tidak terlalu lemah. Biasanya intonasi akan menguat pada hal-hal yang penting.

Gerakan tubuh termasuk indikator paling diperhatikan oleh agen. Para agen sangat memperhatikan gerakan tubuh mereka. Penggunaan tangan yang bebas menjadi perhatian agen setelah tatapan mata mereka kepada nasabah. Dari gerakan tangan dan tatapan mata agen dapat mengetahui kesungguhan calon nasabah dan dari ini juga calon nasabah dapat menangkap kesungguhan dari agen. 
Ara Auza. Pengaruh Komunikasi Nonverbal dalam mewujudkan Komunikasi yang Efektif antara Agen dan

Berbicara mengenai jarak (proksimitas) para agen hanya berbicara tentang dekat. Jarak yang dekat hanya agar suara agen jelas terdengar. Dengan jarak yang ideal adalah jarak dimana calon nasabah tidak merasa terancam oleh kehadiran agen.

Penampilan fisik sangat diperhatikan agen dalam melakukan prospecting. Pakaian rapi dan perhiasan tidak terlalu mencolok memudahkan agen dalam menyakinkan calon nasabah. Penampilan yang menarik dan nyaman bagi agen juga

Permasalahan waktu tidak menjadi prioritas bagi agen. Karena faktor pemilihan waktu tidak ditentukan oleh agen melainkan calon nasabah. Agen hanya akan melakukan prospecting pada hari dan jam yang diinginkan oleh calon nasabah. Durasi dalam prospecting berkisar antara 1-2 jam.

Bau-bauan juga tidak menjadi prioritas bagi agen dalam menampilkan dirinya pada nasabah. Baubauan yang dipilih merupakan karakteristik dari bau-bauan yang biasa dipakai agen. Tidak ada perhitungan khusus tentang bau-bauan, bauan yang membuat nyaman agen maka bau-bauan itu yang akan dipilih sebagai bauan dirinya menumbuhkan rasa percaya diri. Agen berusaha untuk mengurangi streotrip buruk tentang dirinya atau agen asuransi melalui manipulasi penampilan fisiknya. Faktor ini sangat dominan bagi agen, ketika tidak sedang berpakaian rapi maka kebanyakan agen tidak melakukan prospecting.

Pengamatan langsung bertujuan untuk mengamati penggunaan komunikasi nonverbal agen ketika sedang mempresentasikan produk asuransi. Indikator pengamatan meliputi intonasi suara, gerakan tubuh, penampilan fisik, jarak, waktu dan bau-bauan.

Observasi ini dilakukan beberapa kali di dua lokasi. Berikut hasil pengamatan dari peneliti tentang peranan komunikasi nonverbal agen asuransi: pertama, indikator penampilan fisik menjadi indikator dominan para agen untuk menampilkan dirinya kepada calon nasabah, gaya berpakaian, gaya rambut dan pemilihan warna yang terang banyak digunakan agar menumbuhkan keyakinan kepada agen; kedua: intonasi suara dan gerakan tubuh menjadi indikator perantara, hanya digunakan pada saat presentasi.

Intonasi yang jelas dan tegas banyak digunakan agen sedangkan tatapan mata dan gerakan tangan paling banyak digunakan agar calon nasabah tetap fokus dalam mendengar penjelasan agen; ketiga: indikator jarak, waktu, dan bau-bauan menjadi indikator minoritas, agen jarang memperhatikan indikator ini. Pengetahuan yang kurang akan ketiga hal ini mungkin menjadi faktor para agen kurang mempehatikan indikator ini. Pemakaian bau-bauan hanya memakai karakteristik agen.

Pengamatan dilakukan di kediaman ibu Zahraini Jl. Permata Nusa no.15 Villa Malina Indah Pasar III Tanjung Sari, Medan. Pengamatan pertama dilakukan pada tanggal 25 Juni 2011. Asnawi melakukan penandatangan untuk polis atas dirinya.

Setelah penandatanganan informan I mulai menerangkan tentang asuransi untuk anak Asnawi bernama Muhammad Dzilmi. Suasana pada saat prospecting cukup kondusif dan terlihat hangat. Infoman I banyak menggunakan tangan dan tatapan matanya ketika menjelaskan. Intonasinya juga teratur, setiap ada hal yang penting intonasi akan menekan.

Respon dari calon nasabah kepada informan berbentuk senyuman setuju atau anggukan kepala tanda mengerti terhadap apa yang dijelaskan. Respon lain yang diberikan berupa pertanyaan dari ketidakmengertian tentang produk atau hal-hal yang belum jelas. Biasanya berupa pertanyaan mendasar tentang proses klaim dan jumlah premi yang didapat dari investasi, resiko-resiko ke depan melalui kasuskasus kematian atau kecelakaan, berapa besaran klaim.

Penjelasan tentang produk dilakukan berulang-ulang, beberapa kali nasabah juga mengajukan pertanyaan. Jarak yang digunakan merupakan personal atau sepanjang lengan. Nasabah juga merasa nyaman dengan jarak ini. Bauan tidak digunakan oleh Informan I.

Respon dari nasabah adalah positif. Penjelasan dari informan I didengar dengan serius oleh nasabah. Nasabah beberapa kali mengajukan pertanyaan tentang hal yang tidak jelas. Secara keseluruhan prospecting dilakukan selama lebih kurang 45 menit.

Prospecting yang dilakukan Informan I berjalan efektif, karena pada dasarnya Asnawi sudah menjadi nasabah, prospecting yang dilakukan oleh informan I adalah untuk anak

Asnawi yaitu Muhammad Dzilmi. Tidak banyak kendala dalam prospecting ini. Informan menggunakan komunikasi nonverbal secara efektif, yang terlihat jelas adalah enggunaan gerakan tangan, tatapan mata dan intonasi. Penampilan fisik informan sangat santai karena pemilihan tempat adalah 象 http://mahesainstitute.web.id/ojs2/index.php/jehss 
kediamannya dan pemilihan waktu adalah hari Sabtu saat malam hari. Malam hari adalah saat santai, kesan dalam pertemuan ini adalah pertemuan keluarga.

Tanggal 2 Juli disepakati oleh Informan I dan calon nasabah sebagai waktupelaksanaan penandatanganan polis untuk Muhammad Dzilmi. Pemilihan waktu dan pemilihan tempat hampir sama seperti pertemuan pertama. Suasana juga terlihat lebih santai, namun dalam pertemuan ini tidak banyak disinggung lagi tentang asuransi. Informan I dan nasabah lebih banyak berbicara tentang tema keluarga. Pada pertemuan kedua terlihat bagaimana komunikasi antar pribadi dan komunikasi nonverbal yang dilakukan informan menimbulkan hubungan yang makin dekat. Secara historis keduanya adalah keluarga, namun karena kesibukan jarang melakukan komunikasi. Prospecting yang dilakukan efektif menimbulkan hubungan yang makin baik antara keduanya.

Hasil pengamatan dapat dilihat para agen sering menggunakan komunikasi nonverbal mereka ketika sedang berhadapan dengan nasabah. Namun, banyak dari agen kurang memahami tentang pentingnya komunikasi nonverbal dalam pesan yang mereka sampaikan. Mereka lebih terfokus pada pesan verbal berbentuk lisan dan tulisan dari produk asuransi. Agen menjelaskan secara detail tentang profit yang akan didapat oleh nasabah dari investasi di asuransi.

\section{Komunikasi Efektif}

Komunikasi nonverbal yang dilakukan agen memudahkan nasabah untuk memahami produk asuransi. Keunggulan dan keuntungan dalam asuransi yang ditekankan oleh agen dipahami secara baik oleh nasabah. Nasabah memahami keuntungan itu secara utuh. Pemahaman yang utuh akan keuntungan itu menyakinkan nasabah untuk menanamkan modalnya.

Pengertian yang sama meningkatkan hubungan antara agen dan nasabah. Agen diuntungkan dengan kehadiran nasabah dan nasabah merasa sangat tertolong oleh pencerahan yang dilakukan agen. Nasabah beranggapan merasa terbantu dengan adanya agen yang mengenalkan kepadanya tentang asuransi. Resiko kehidupan masa depan dapat teratasi oleh kehadiran asuransi yang dibawa oleh agen.

Sifat holistic antara bahasa verbal dan bahasa nonverbal banyak mempengaruhi keefektifan pesan yang disampaikan. Proses prospecting merupakan proses interaksi utama ketika informan menjelaskan tentang asuransi kepada calon nasabah. Pesan yang disampaikan informan baik secara verbal dan noverbal banyak berbicara tentang produk dan keunggulan AXA, sementara interaksi dari calon nasabah biasanya berbentuk senyuman tanda mengerti dan anggukan kepala. Respon lain yang dilakukan calon nasabah berbentuk pertanyaan tentang produk yang kurang jelas dan atau resiko dan proses klaim, dll.

Kedudukan pesan verbal dan nonverbal dapat kita lihat dari sifat holistic keduanya. Pesan verbal akan terasa datar ketika tidak diikuti pesan nonverbal, begitu juga sebaliknya. Informan menggunakan pesan verbal dan nonverbal secara bersamaan. Kedua pesan ini saling melengkapi untuk menghasilkan pesan yang mudah dipahami nasabah. Pesan verbal dan nonverbal berpengaruh dalam menciptakan komunikasi efektif antara agen dan nasabah. Strategi komunikasi tatap muka dengan nasabah, agen akan lebih mudah menyampaikan pesannya dengan menggunakan pesan verbal dan pesan nonverbal.

Alat bantu yang digunakan oleh informan untuk menjelaskan pada calon nasabah hanya berupa proposal mengenai produk. Lebih dalam berbicara antara komunikasi efektif antara informan dan nasabah banyak terjadi dalam ruang-ruang informal lain. Proses prospecting hanya salah satu bagian dari banyak bagian komunikasi antar pribadi. Komunikasi nonverbal hanya dilakukan pada saat prospecting, dan komunikasi verbal juga terpengaruh oleh bahasa verbal yang dilakukan.

\section{SIMPULAN}

Hasil penelitian Komunikasi nonverbal yang sering digunakan oleh agen adalah penampilan fisik. Penampilan fisik yang rapi dan menarik banyak diperhatikan agen. Faktor yang dominan ketika melakukan presentasi adalah intonasi/nada suara yang jelas dan gerakan anggota tubuh/kinesik seperti tangan dan tatapan mata.

\section{DAFTAR PUSTAKA}

Birowo, M.A. (2004). Metode Penelitian Komunikasi: Teori dan Aplikasi. Yogyakarta: Gitanyali.

Borg, J. (2009). Buku Pintar Memahami Bahasa Tubuh. Jogjakarta: Think.

Bungin, B. (2005). Sosiologi Komunikas. Jakarta: Kencana Prenada Media Group.

Bungin, B. (2005). Metodologi Penelitian Kuantitatif. Jakarta: Kencana Prenada Media Group. 
Ara Auza. Pengaruh Komunikasi Nonverbal dalam mewujudkan Komunikasi yang Efektif antara Agen dan

Cangara, H. (2006). Pengantar Ilmu Komunikasi. Jakarta: Raja Grafindo Persada.

Effendy, O.U. (1999). Ilmu Komunikasi Teori dan Praktik. Bandung: Remaja Rosdakarya.

Hasyim, A.A. (1995). Pengantar Asuransi. Jakarta: Bumi Aksara.

Kriyantono. (2007). Teknik Praktis Riset Komunikasi. Jakarta: Kencana.

Liliweri, A. (1991). Komunikasi Antar Pribadi. Bandung: Citra Aditya Bakti

Lubis, A.Y. (2003). Paul Feyerabend: Penggagas Antimetode. Jakarta: Teraju.

Muhammad, A. (2007). Komunikasi Organisasi. Jakarta: Bumi Aksara.

Mulyana, D. (2005). Ilmu Komunikasi: Suatu Pengantar. Bandung: Remaja Rosdakarya

Nasution, M.A. dkk. (2008). Metode Penelitian. Medan: USU Press

Nawawi, H. (1995). Metode Penelitian Bidang Sosial. Yogyakarta: Gajah Mada University Press.

Purba, A. dkk. (2006). Pengantar Ilmu Komunikasi. Medan: Pustaka Bangsa Press.

Rakhmat, J. (2005). Psikologi Komunikasi. Bandung: Remaja Rosdakarya.

Samovar, L.A. \& Potter, R.E. (1991). Communication Between Cultures. Belmont, California: Wadsworth.

Sendjaja, S.D. (2005). Teori Komunikasi. Jakarta: Universitas Terbuka.

Singarimbun. M. \& Effendi, S. (2006). Metode Penelitian Survei. Jakarta: LP3ES.

Stakes, J. (2007). How to do Media and Cultural Studies. Bandung: Bentang.

West, R. \& Turner, L.H. (2009). Pengantar Teori Komunikasi: Analisis dan Aplikasi. Jakarta: Salemba Humanika.

(http://www.google.com/publicdata?ds=wbwdi\&met=sp_pop_totl\&idim=country:IDN\&dl=id\&hl=id\&q=jumlah+p enduduk+indonesia) 07 April 2011 pukul 19.05.30

http://www.axa-financial.co.id. 07 April 2011 pukul 19.10.28

http://asuransijiwaaxa.wordpress.com/. 07 April 2011 pukul 19.02.57

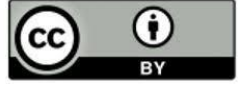

